\title{
Comunicação
}

[Communication]

\section{Cisticercose em animais abatidos em Sabáudia, Estado do Paraná}

\author{
[Cysticercosis in animals of Sabáudia, Paraná State]
}

\section{A.L. Falavigna-Guilherme, K. Silva, S. M. Araújo, M.L. Tobias, D.L.M. Falavigna}

Laboratório de Parasitologia Ambiental - UEM

Av. Colombo, 5790

87020-900 Maringá - PR

A cisticercose bovina e suína é uma infecção causada por larvas de Taenia saginata e Taenia solium, respectivamente, a partir da ingestão de ovos viáveis presentes no meio ambiente contaminado com fezes humanas (Gusso, 1994). A cisticercose pode acometer diferentes órgãos e sistemas como coração, pulmão, fígado, tecido subcutâneo, musculatura esquelética, globo ocular e sistema nervoso central (Canelas, 1962).

Os suínos infectados desempenham papel fundamental na transmissão e manutenção do complexo teníase/cisticercose para o homem (Coulibaly e Yameogo, 2000). A cisticercose humana é um grave problema de saúde em várias regiões da Ásia, África e América Latina, particularmente nos países em desenvolvimento, onde a precariedade das condições de saneamento básico e o baixo nível socioeconômicocultural favorecem sua disseminação (Agapejev, 2003). No Brasil, a cisticercose tem caráter endêmico nos estados de São Paulo, Minas Gerais, Paraná e Goiás (Livramento et al, 1993).

O controle da teníase/cisticercose depende das condições econômicas, sociais e culturais de cada local (Esteves et al, 2005). Na década passada, no estado do Paraná, foram criados e implantados programas para a redução do complexo teníase/cisticercose em todo o estado, a partir de campanhas de conscientização, vigilância sanitária e epidemiológica (Boletim..., 2002). Também foram implantados abatedouros públicos municipais a fim de controlar os abates clandestinos que ocorriam nas áreas rurais, evitando o consumo de carnes contaminadas (Boletim..., 2002).

O município de Sabáudia, localizado na região noroeste do estado do Paraná, possui um abatedouro municipal de bovinos e suínos a serem distribuídos para açougues e pequenos mercados da região. O município conta com uma população de 4644 habitantes, e as atividades predominantes são a pecuária e o cultivo de soja e milho (Instituto..., 2000). O objetivo deste trabalho foi verificar a ocorrência de cisticercose em gados bovino e suíno sacrificados no abatedouro municipal de Sabáudia.

O estudo observacional foi realizado a partir da coleta diária durante o abate de bovinos e suínos no Abatedouro Municipal de Sabáudia, sob o controle do Serviço de Inspeção Federal (SIF), no período de janeiro a dezembro de 2004. Os dados foram coletados por meio de questionário, contendo informações sobre o número de animais abatidos/dia, número de animais com presença de cisticerco, número e localização de cisticercos por animal.

O número de suínos abatidos foi maior que o de bovinos. De 1046 suínos abatidos, nenhum apresentou larvas de cisticerco, mas 36/389 $(9,3 \%)$ dos bovinos estavam contaminados. O masseter foi o local mais parasitado (19), seguido por coração (14), língua (4) e fígado (2). 
Os padrões implantados junto com o programa de controle de teníase/cisticercose que o Paraná vem desenvolvendo, desde 1994 (Boletim..., 2002), com certeza contribuíram para evitar a cisticercose suína.

Os dados referentes aos bovinos revelaram baixa contaminação por cisticercos. Os bovinos, diferentemente dos suínos, criados em pecuária extensiva, tinham acesso aos mananciais aquáticos e espaços abertos, onde podem ter sido contaminados por ovos de Taenia saginata veiculados por fezes humanas. Como medida de controle, o abatedouro de Sabáudia mantém as peças dos animais congeladas à temperatura de $5^{\circ} \mathrm{C}$ por dez dias consecutivos. A inviabilidade do cisticerco pode ocorrer com a cocção ou fervura acima de $90^{\circ} \mathrm{C}$ por quatro horas ou o congelamento de $-5^{\circ} \mathrm{C}$ por quatro dias (Manual..., 2002).

A baixa contaminação em bovinos reforça a eficiência das medidas de controle realizadas no Paraná. Entretanto, é necessária a educação continuada principalmente da população humana, fonte de contaminação, enfatizando aspectos da epidemiologia e do controle do complexo teníase/cisticercose.

\begin{abstract}
The aim of this work was to verify the occurrence of bovine and swine cysticercosis in animals slaughtered at the Abatedouro Municipal de Sabáudia, Paraná State. The number of daily-abated animals, the number of animals with cysticercus and the number and location of the cysticercus in the animals in a period of twelve months were collected. From 1046 swines slaughtered none showed cysticercus, but 36/out of 389 bovines (9.3\%) were contaminated. Head was the most parasited region, followed by heart, tongue and liver. The absence of contamination observed in swines and the low contamination of the bovines reinforce the efficiency of the control measures accomplished in Paraná State.
\end{abstract}

Keywords: swine, bovine, cysticercosis, slaughterhouse, Paraná State

\section{REFERÊNCIAS BIBLIOGRÁFICAS}

AGAPEJEV, S. Aspectos clínicos epidemiológicos da neurocisticercose no Brasil - análise crítica. Arq. Neuropsiq., v. 60, p. 211-218, 2003.

BOLETIM EPIDEMIOLÓGICO. Secretaria de Saúde do Estado do Paraná, v. 5, n.16, 2002. Disponível em: http//www.saúde.pr.gov.br. Acessado 10 jun. 2005.

CANELAS, H.M. Neurocisticercose: incidência, diagnóstico e formas clinicas. Arq. Neuropsiq., v. 20, p.1-16, 1962.

COULIBALY, N.D.; YAMEOGO, K.R. Prevalence and control of zoonotic diseases: collaboration between public health workers and veterinarians in Burkina Faso. Acta Tropica, v. 76, p. 53-57, 2000.

ESTEVES, F.M.; SILVA-VERGARA, M.L.; CARVALHO, A.C.F.B. Inquérito epidemiológico sobre teníase em população do programa saúde da família no município de Uberaba, MG. Rev. Soc. Bras. Med. Trop., v.38, p. 530-531, 2005.
GUSSO, R.L.F. Teníase e Cisticercose. In: ENCONTRO DO CONE SUL E SEMINÁRIO LATINO AMERICANO, 1.,1994. Anais....Curitiba: OPAS/UFPR, 1994. p.17. (Resumo).

INSTITUTO BRASILEIRO DE GEOGRAFIA E ESTATÍSTICA, 2005 Disponível em: htpp//www.ibge.gov.br/estatistica/populacao/censo200 0/sabaudia. Acessado em 20 nov. 2005.

LIVRAMENTO, J.A.; MACHADO, L.R.; SPINAFRANÇA, A. Immunobiology of neurocysticercosis. In: FEJERMAN, N.; CHAMOLES, N. A. (Ed). New trends in pediatric neurology. Amsterdam: Elsivier, 1993. p. 307-312.

MANUAL de vigilância ativa de doenças transmitidas por alimentos/Taenia saginata/Teníase. São Paulo, 2002. Disponível em: http:/www.cve.saúde.sp.gov.br. Acessado em 18 out. 2006. 